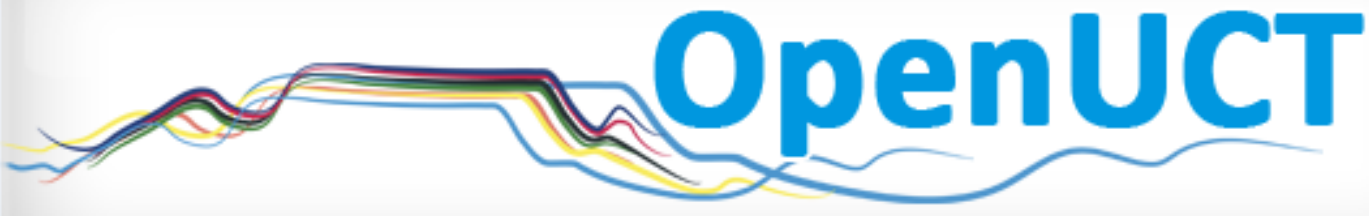

This is the author-approved manuscript version of a journal article published in:

Smith, L.C. 2009. Measuring the success of an academic development programme: a statistical analysis. South African Journal of Higher Education. 23(5): 1009-1025.

It is made available under the terms of agreement between the author and the journal, and in accordance with the University of Cape Town's Open Access Policy for the purposes of research, teaching and private study.

http://www.openuct.uct.ac.za/sites/default/files/UCTOpenAccessPolicy.pdf 


\title{
Measuring the success of an academic development programme: A statistical analysis
}

\author{
L. C. Smith
}

Centre for Higher Education Development University of Cape Town South Africa e-mail: Leonard.Smith@uct.ac.za

\begin{abstract}
This article uses statistical analysis to estimate the impact of first-year academic development courses in microeconomics, statistics, accountancy, and information systems, offered by the University of Cape Town's Commerce Academic Development Programme, on students' graduation performance relative to that achieved by mainstream students. The data for four cohorts, covering the years 1999-2002 is pooled. The results suggest that membership of the academic development programme enables students to out-perform their peers on the mainstream controlling for a number of independent variables, and that the positive effect of the first-year courses on graduation performance is particularly pronounced for African students. The implications of these findings for higher education in South Africa are considered.
\end{abstract}

\section{INTRODUCTION}

Academic development programmes and courses have been used extensively in South African higher education institutions over the last 25 years. These have taken a variety of forms including bridging courses, extra tutorials and additional courses, usually in English and mathematics (Walker and Badsha 1993; Volbrecht 1999; Edwards 2000; Smith 2004; Smith and Edwards 2007). The main aim of these interventions is to enable students from disadvantaged academic and socioeconomic backgrounds to develop their literacy, quantitative and study skills so that they are able to achieve success in a particular course, and ultimately, a higher education qualification.

However, despite the pervasiveness of these interventions it is fair to say that relatively few South African studies have tested the effectiveness of a development course or programme, in the commerce faculty, in improving students' performance in individual courses and their graduation rates (Smith 2004; Smith and Edwards 2007; Smith 2009).

Taking economics as an example, the focus of the earlier studies was to explain why academically disadvantaged students failed the first-year economics course (Banach, Fuzile and Rampedi 1992; Hesketh, Mbali and Mkhize 1994). These studies were largely analytical, or used simple correlation analysis. Smith (2004), Smith and Edwards (2007) and Smith (2009) tested the efficacy of an academic development course in first-year microeconomics, at the University of Cape Town, relative to a control group drawn from the mainstream. The efficacy of the course was measured in terms of course success in the current and in subsequent courses in economics, conditional on a number of control variables. The key findings were that students on the academic development course outperformed mainstream students in the first-year course, and that they outperformed the same students by an average of 12 percentage points for the structured/essay questions in the second-year microeconomics examination. This result suggests that the skills acquired in academic development courses persist into further years. 
Turning to the evaluation of commerce academic development programmes, Ayaya (1996) used ordinary least squares (OLS) to investigate the influence of 29 explanatory variables, including students' first-year weighted mean marks, ${ }^{2}$ on academic performance of students in a Bachelor of Commerce programme at the National University of Lesotho for the period 1982/83-1991/92. He concluded that the transition programme was successful. However, this conclusion does not seem warranted as there was no control group, and it seems more likely that the transition-year weighted mean mark was primarily a measure of academic ability.

Curtis and De Villiers (1992) and De Villiers and Rwigema (1998) used a mainstream control group to evaluate the success of a bridging year for commerce undergraduates at the University of the Witwatersrand. Students selected for this study had all attended schools falling under the now defunct Department of Education and Training (DET). ${ }^{3}$ Curtis and De Villiers (1992) used OLS analysis to establish that students who attended the bridging course achieved 7.7 percentage points more than their peers on the mainstream, after controlling for differences in admission rating. ${ }^{4}$ De Villiers and Rwigema (1998) looked at the effect of the bridging year on the graduation success compared to those ex-DET students who had followed the mainstream programme. To the author's knowledge, this is the first South African study that attempted to evaluate the long-term effect of a first-year academic development course or programme. They showed, controlling for the admission rating, that bridging-programme attendance had a positive and statistically significant effect for each of the four periods to graduation.

Both studies suffer from selection bias in that students were chosen for the bridging programme on the basis of a number of criteria, including their admission rating. Ideally, the pool of ex-DET students should have been randomly allocated between the bridging programme and the mainstream. Also, De Villiers and Rwigema (1998) used OLS analysis with a binary dependent variable. This can result in heteroskedastic non-normal error terms. In this instance, logit or probit models should be used.

The lack of research into the effectiveness of academic development courses and programmes is not unique to the South Africa. There is an extensive literature on the use, and evaluation, of support (remediation) programmes in colleges in the United States (Ramirez 1997; Weismann, Bulakowski and Jumisko 1997; Boylan and Saxon 1999; Brothen and Wambach 2004; Bettinger and Long 2005). However little research has been undertaken to test the efficacy of these programmes and much of what has been done is flawed in terms of its design (O'Hear and MacDonald1995; MacDonald and O'Hear 1996; Boylan and Saxon 1999; Bettinger and Long 2006; Levin and Calcagno 2008).

That said, the research that has been undertaken suggests that there are benefits to students who attend academic development courses (Boylan and Saxon 1999). Students who successfully complete remedial courses develop their literacy and numeracy skills, they are able to pass mainstream courses in the subject areas, and they are less likely to drop out (they exhibit higher persistence rates) relative to comparable mainstream cohorts. However, relatively few studies use graduation as the dependent variable (Adelman 1999). 
That few studies have used graduation as the dependent variable seems surprising given the cost of funding such courses and programmes and the pressure on higher education institutions to improve their students' academic performance, specifically their throughput (graduation) rates (Adelman 1999; Saxon and Boylan 2001; Hay and Marais 2004). What society expects and government pays for, in South Africa at least, are graduates (Visser and Hanslo 2005).

The aim of this study is to test the efficacy of the first-year academic development courses in microeconomics, accountancy, statistics and information systems offered by the University of Cape Town's Commerce Academic Development Programme (CADP) on students' graduation performance. Statistical analysis is used to test whether students on the CADP outperformed mainstream students through to graduation conditional on a number of independent variables.

The study addresses three areas previously neglected in the literature on academic development in South Africa. Firstly, the focus is on graduation rates. Secondly, an explicit attempt is made to compare the performance of academic development students with a control group drawn from the mainstream; only then is it possible to quantify the degree to which the CADP has improved student performance through to graduation. Thirdly, some of the variables that help explain graduation performance are identified.

The structure of the article is as follows. In Section 2 the CADP is described. In Section 3 the empirical methodology used in this article is presented and Section 4 analyses the data used and discusses the results. Section 5 considers the implication of the findings for higher education policy in South Africa, and Section 6 concludes the article.

\section{THE COMMERCE ACADEMIC DEVELOPMENT PROGRAMME (CADP)}

Prior to 1982 all students at the University of Cape Town were expected to do the mainstream courses; no additional support was given to students from disadvantaged backgrounds. In 1982 the university introduced the Commerce Academic Support Programme (CASP). This programme, renamed the Commerce Academic Development Programme (CADP) in 1987, is designed for students who do not have sufficient matriculation points to be accepted into the Commerce Faculty, are considered to come from academically and socio-economically disadvantaged backgrounds, and are reckoned to have the potential, given the right environment, to achieve a Bachelor of Commerce degree. Prior to 1995, CADP students registered for the mainstream courses. They were required to attend additional (supplementary) courses to help them compensate for critical gaps in their education. For example, they were required to attend a whole-year English language course and a double-period economics tutorial running alongside the mainstream course.

However, even with this support, students from academically disadvantaged backgrounds struggled to pass the mainstream courses. Contributing factors were the pace of the one-semester courses and the students' poor English language, quantitative, writing and study skills. In 1995 the university responded to this situation by introducing a four-year Bachelor of Commerce degree for CADP students. This 
allowed both the Department of Accounting and the School of Economics to introduce first-semester introductory courses in accounting and economics, respectively. However, academic development students continued to struggle with the pace of the single-semester first-year mainstream courses as their relative deficiencies with respect to learning, English language, writing and quantitative skills were not adequately addressed in the half-year courses. Therefore, in 1999 the CADP introduced whole-year first-year courses in microeconomics, accounting, statistics and information systems.

Students who successfully completed the four first-year courses moved on into mainstream courses. Very little additional support was given to the CADP students; they were left to 'sink or swim'. Thus, this study tests the effectiveness of academic interventions in the first-year in enabling students to graduate relative to the performance of mainstream students.

Subsequent to 2003 the CADP introduced several additional interventions at multiple levels throughout the degree programme, which have grown over time in number and complexity (Pym 2007). These include regular class meetings, workshops in second-year microeconomics and macroeconomics, mentorship programmes, an awards evening, an orientation programme, courses in study and life skills, and work experience programmes. This more holistic approach to academic development is aimed at enhancing the academic performance of students through to graduation and developing a positive image of the CADP in the minds of academic development students. It is only possible to analyse the effectiveness of these additional interventions in 2010 when the 2003-2005 cohorts will have passed through the system.

\section{EMPIRICAL METHODOLOGY Specification}

The aim of this article is to compare the graduation rates of CADP students relative to their peers on the mainstream conditional on a number of independent variables. The data for four years (1999-2002) is pooled, which results in a more robust set of estimations than is previously the case. The student's career at university is viewed as a production process whereby graduation performance is a function of a variety of inputs (Edwards 2000; Smith and Edwards 2007; Smith 2009). This relationship can be represented as:

OUTPUT $=$ F $($ CADP, STUDENT, MATRICULATION PERFORMANCE, SCHOOL) (1) where:

OUTPUT is whether the student graduated or not; CADP is a dummy variable that equals 1 for CADP students; STUDENT includes variables measuring students' characteristics; MATRICULATION PERFORMANCE includes variables measuring performance in school-leaving subjects; SCHOOL includes variables for different types of schools.

The statistical programme, STATA, is used to conduct propensity score matching. In essence, this approach is used to estimate the probability that each of the observations in the mainstream control group falls into the treatment group (CADP) across a set of identified independent variables. The 
performance of the CADP cohort is then estimated relative to the control group constructed using this matching process. This method is used to estimate whether the academic development type educational interventions in the first-year academic development courses enables the CADP cohort to achieve a higher graduation rate than the mainstream cohort, conditional on the independent variables.

Multivariate analysis is also used to estimate the effect of the educational interventions on the graduation performance of the CADP cohort relative to the mainstream cohort. In addition, it makes possible the investigation of the role of each of the independent variables on students' graduation performance. The statistical programme, EVIEWS, is used to conduct this analysis.

A dummy variable, CADP, equal to 1 for the CADP cohort, is used to assess the effectiveness of the CADP on students' graduation performance. A positive sign for the coefficient of the CADP dummy suggests that the academic development programme exerts a positive influence on students' graduation performance relative to that of the mainstream students.

To obtain the conditional impact of CADP on graduation performance, a number of variables that are thought to capture students' ability, knowledge and skills that facilitate graduation are treated as independent variables. These variables include performance in school-leaving subjects, schools attended and student characteristics.

Proxies for academic ability are important in explaining students' academic performance at university. Following Edwards (2000), Smith (2004), Van Walbeek (2004), Smith and Edwards (2007) and Smith (2009), a modified version of the matriculation points score is used as a measure of academic ability. ${ }^{5}$ Independent variables are included for English ( $\left.\mathrm{HG}\right)$ and mathematics $(\mathrm{HG})$; therefore, the points allocated to mathematics HG and SG, and English first and second language (HG) are deducted to derive the adjusted matriculation points score. Two points are also deducted from the matriculation points score in respect of physical science $(\mathrm{HG})$, as this subject is also treated as an independent variable. The coefficient of the adjusted matriculation score is expected to be positive and statistically significant.

Competence in mathematics and physical science is generally found to be strongly associated with performance in economics at least (Van Walbeek 2004; Parker 2006; Smith and Edwards 2007; Smith 2009). Dummy variables for each of these school-leaving subjects are included. The coefficients of these two variables are expected to be positive and statistically significant.

There are grounds for expecting English (home language) to have a positive impact on graduation performance at universities where English is the medium of instruction. However, the evidence regarding the significance of English (home language), as regards the study of economics at least, is inconclusive (Edwards 2000; Smith 2004; Van Walbeek 2004; Parker 2006; Smith and Edwards 2007; Smith 2009). A dummy variable equal to 1 is included if the student's home language is English. There is no a priori expectation as regards the sign of the coefficient for this variable.

Four other variables are included: gender, age at entry, school attended, and whether the student was previously classified as 'white'. A dummy variable equal to 1 is included if the student is male. There is 
no a priori expectation as regards the sign of the coefficient for this variable. It is suggested that there is a positive relationship between students' age and academic performance; older students are more likely to have achieved the level of intellectual development necessary for mastering abstract processes (McConnell 1980). However, the evidence regarding the significance of students' age, as regards the study of economics, is inconclusive (Park and Kerr 1990; Tay 1994; Van Walbeek 2004; Parker 2006). Age is included as a continuous variable measured in years to the first decimal place. There is no a priori expectation as regards the sign of the coefficient for this variable. Dummy variables, equal to 1 , are included for schools that in the apartheid era fell under the Department of Education and Training (DET), and the Houses of Representatives and Delegates (COHR). It is expected that students from former DET and COHR schools will under-perform students who attended private and Model C schools.

A dummy variable, equal to 1 , is included for students previously classified as 'white' on the grounds that many advantages accrued to members of the white population under the apartheid system (Terreblanche 2002). These advantages make it more likely that white children in South Africa have access to material resources that are unavailable to other children. They are more likely to have parents who themselves have a tertiary qualification. Also, they are more likely to come from family backgrounds where it is expected that they will go to university. It is expected that the coefficient of this variable will be positive and statistically significant.

\section{Estimation issues and limitations}

This study compares the graduation performance of CADP students with that of their peers on the mainstream. However, there are a number of sample selection issues, which are discussed below.

Variables such as students' effort, attitude and motivation are omitted as it is difficult to find suitable proxies. The omission of these variables may result in biased estimates of the coefficients. In particular, if these omitted variables are positively correlated with the CADP dummy, their effect on graduation performance may be erroneously attributed to the CADP dummy variable.

Another important consideration relates to possible sample-selection problems. The mainstream students can only act as a control group if they are drawn from the same population as the CADP cohort across a broad range of characteristics. If not, the difference in the performance of the CADP cohort might be due to their differing set of characteristics rather than the effectiveness of the CADP. To test for the extent of the similarity between the two cohorts, differences of means and proportions tests were conducted for each of the continuous and discrete variables. The results of this analysis are presented in Table 1. 
Table 1: Control variables

\begin{tabular}{|c|c|c|c|}
\hline & CADP & Mainstream & Tests \\
\hline Personal characteristics & $\%$ share & $\%$ share & z-test \\
\hline African & 74.0 & 16.6 & $20.9^{* *}$ \\
\hline Indian & 4.8 & 9.5 & $2.3^{*}$ \\
\hline Coloured & 21.1 & 13.2 & $3.4^{* \star}$ \\
\hline White & 0.0 & 60.6 & \\
\hline English home language (Enghome) & 24.2 & 81.0 & $19.8^{* *}$ \\
\hline \multirow[t]{2}{*}{ Male } & 50.7 & 55.6 & 1.4 \\
\hline & Mean & Mean & t-test \\
\hline Age at entry & 18.3 & 18.6 & $3.9^{*}$ \\
\hline School attended & $\%$ share & $\%$ share & z-test \\
\hline Model C & 18.9 & 46.5 & $8.1^{\star *}$ \\
\hline Private & 6.6 & 37.0 & $9.3^{* *}$ \\
\hline $\mathrm{COHR}$ & 23.8 & 7.8 & $8.2^{* \star}$ \\
\hline DET & 43.2 & 3.1 & $25.4^{\star *}$ \\
\hline Matriculation performance & Mean & Mean & t-test \\
\hline Mean matriculation points score (Matpt) & 32.0 & 40.1 & $29.7^{*}$ \\
\hline $\begin{array}{l}\text { Mean adjusted matriculation points score } \\
\text { (Adjmatpt) }\end{array}$ & 21.8 & 26.6 & $23.9^{*}$ \\
\hline Matriculation subjects & $\%$ share & $\%$ share & z-test \\
\hline English first language (HG) (Eng FL HG) & 41.4 & 94.8 & $27.9^{\star \star}$ \\
\hline Mathematics (HG) (Math HG) & 34.8 & 84.8 & $18.9^{* *}$ \\
\hline Physical science (HG) (PS HG) & 22.5 & 74.4 & $16.7^{* *}$ \\
\hline \multicolumn{4}{|l|}{ Year } \\
\hline 1999 & 27.8 & 23.7 & 1.4 \\
\hline 2000 & 19.4 & 24.6 & 1.8 \\
\hline 2001 & 31.7 & 27.6 & 1.3 \\
\hline 2002 & 21.1 & 24.0 & 0.9 \\
\hline Observations & 227 & 3428 & \\
\hline
\end{tabular}

Note: ${ }^{* *}$ and * Statistically significant at the $1 \%$ and $5 \%$ levels, respectively. The column titled 'Tests' provides the t- and z-statistics for the tests of equality of means and proportions between the CADP and mainstream cohorts.

It is clear that the two cohorts differ markedly from one another; in nearly all cases the null hypothesis of equal means or proportions can be rejected. For example, the mean matriculation points score for the mainstream cohort is greater than the mean score for the CADP cohort, and is 
statistically significant at the 1 per cent level. The proportion of students who have English as their home language is greater for the mainstream cohort. African students make up a larger proportion of the CADP cohort. Importantly, the mainstream cohort shows a strong bias towards mathematics (HG), English first language (HG) and physical science (HG). All these differences are statistically significant at the 1 per cent level.

Two approaches are taken to deal with the sample selection problem. The first is to use a statistical programme, STATA, to conduct propensity score matching, as described above. Secondly, multivariate analysis is used to estimate the effect of the CADP on graduation rates conditional on the independent variables discussed above.

However, as noted by Edwards (2000), the extent of the sample-selection problem may not be very significant. There may be substantial random error associated with the main variable used to select students into the CADP, namely matriculation grades. The matriculation examinations differ, and the papers are graded by teams of examiners, across provinces. Therefore, it is probable that some students end up doing the three-year programme when they should be on the academic development programme and vice versa. Nonetheless, due consideration must still be given to potential sample-selection problems when interpreting the results.

\section{DATA AND RESULTS}

\section{Analysis of data}

This section compares the graduation performance of the CADP and mainstream students for the years 1999-2002. The cohorts include students who began their university career in the Commerce Faculty. To improve the 'match' between the mainstream and CADP cohorts only students who are South African citizens and who wrote the matriculation examination set by one of the nine provinces are included. The data are presented in Table 2. The CADP cohort consists of 227 students and the mainstream cohort consists of 3428 students.

Table 2: Graduation performance of the CADP and mainstream cohorts

\begin{tabular}{|l|c|c|c|}
\hline & CADP & Mainstream & z-stat \\
\hline Grapluation performance & $\%$ & $\%$ & \\
\hline Graduated & 44.1 & 77.1 & $11.1^{*}$ \\
\hline Graduate 3 years & 1.3 & 10.3 & $4.4^{*}$ \\
\hline Graduate 4 years & 15.9 & 50.4 & $10.1^{*}$ \\
\hline Graduate 5+ years & 26.9 & 16.4 & $4.1^{*}$ \\
\hline Excluded & 39.2 & 10.1 & $13.1^{*}$ \\
\hline Observations & 227 & 3428 & \\
\hline
\end{tabular}

Note: * Statistically significant at the $1 \%$ level. 
The results show that the CADP students achieved a much lower graduation rate than their peers on the mainstream. 44.1 per cent of the CADP cohort graduated as opposed to 77.1 per cent of mainstream students. The difference is significant at the 1 per cent level. A much higher proportion of CADP students were excluded. It is not surprising that CADP students take longer to complete their degrees; they are on a four-year rather than a three-year programme.

\section{Estimation results}

The first estimation involves the use of propensity score matching to construct a control group using the mainstream observations. The purpose of propensity score matching is to have a control group that shows a greater similarity to the treated group (CADP cohort) across the range of independent variables. To facilitate the matching process, the matriculation points score is used in place of the adjusted matriculation points score, English first language (HG), mathematics (HG) and physical science (HG). In addition the variable, White, is excluded from the matching process. If this is not done then the observations for all the students previously classified as 'white' are eliminated from the estimation. This is the result of there being no white students on the CADP. Thus the sample size is larger than would otherwise be the case. The result of this estimation is presented in Tables 3 and 4 .

Table 3: Result of the propensity score matching probit estimation

\begin{tabular}{|l|c|c|}
\hline Variable & Estimation 3 Probit & Estimation 3 z-stat \\
\hline C & 12.68 & $13.31^{*}$ \\
\hline Matpt & -0.26 & $7.95^{*}$ \\
\hline Age & -0.26 & $7.01^{*}$ \\
\hline D Male & -0.84 & 1.55 \\
\hline D COHR & -0.17 & $7.81^{*}$ \\
\hline D DET & 1.05 & $9.01^{*}$ \\
\hline D Year 2000 & 1.30 & 0.47 \\
\hline D Year 2001 & -0.77 & $2.86^{*}$ \\
\hline D Year 2002 & 0.40 & $4.14^{*}$ \\
\hline Pseudo R2 & 0.67 & \\
\hline Observations & 0.483 & \\
\hline
\end{tabular}

Notes: * Statistically significant at the $1 \%$ level. 
Table 4: Result of the propensity score matching difference of means estimation

\begin{tabular}{|l|c|c|c|c|c|}
\hline $\begin{array}{l}\text { Dependent } \\
\text { Variable }\end{array}$ & Sample & $\begin{array}{c}\text { Treated } \\
\text { CADP }\end{array}$ & $\begin{array}{c}\text { Controls } \\
\text { Mainstream }\end{array}$ & Difference & t-stat \\
\hline Graduation & Unmatched & 0.44 & 0.77 & -0.33 & $11.33^{\star *}$ \\
\hline & ATT & 0.44 & 0.31 & 0.13 & $2.25^{\star}$ \\
\hline
\end{tabular}

Notes: ${ }^{* *}$ and ${ }^{*}$ represent statistical significance at $1 \%$ and $5 \%$ levels, respectively. ATT: Average treatment effect on the treated.

The sign of the coefficients in Table 3, and whether they are statistically significant, indicate the probability that students in the CADP cohort would qualify for membership of the control group. For example, the coefficient for the matriculation points score (Matpt) is negative and statistically significant at the 1 per cent level. This implies that the CADP cohort has a lower matriculation points score than the mainstream cohort, on average, and that there is a very small probability that CADP students would achieve membership of the mainstream cohort on the basis of their matriculation points score. The same finding holds for age and English home language (Enghome). The coefficients for the dummies for the two types of school, COHR and DET, are positive and statistically significant. This implies that a greater proportion of the CADP cohort attended these two types of school and a small probability that CADP students would achieve membership of the mainstream cohort on the basis of the school they attended. These findings are consistent with the data presented in Table 1. Therefore, although the treated and untreated populations are now more alike, it cannot be said that the groups come from the same population; the propensity score matching technique has not eliminated the sample selection problem.

Turning to Table 4 the graduation rate for the CADP cohort is lower than for the mainstream and the difference is statistically significant at the 1 per cent level. However, the CADP out-performs the control group after is has been subjected to the propensity score matching technique, and the difference is significant at the 5 per cent level. This may suggest that the CADP students derived some benefit from the four first-year whole-year courses in economics, accounting, statistics and information systems that translated into higher graduation rates, conditional on the selected independent variables.

Multivariate analysis is also used to evaluate the impact of the CADP on graduation performance. The production function represented by equation (1) is estimated using a logit model (binary dependent variable) and a selection of the variables in Table 1 as explanatory variables (Estimation 1). Further, an extended specification is estimated that includes the interaction between the CADP $(D C A D P)$ and the following variables; African (D African), Indian (D Indian), DET (D DET) and COHR (D COHR) (Estimation 2). Table 5 presents the results of these two estimations. 
Table 5: Results of the logit model estimations

\begin{tabular}{|c|c|c|c|c|}
\hline Variable & $\begin{array}{c}\text { Estimation } 1 \\
\text { Logit }\end{array}$ & Estimation $1 \mathrm{z}$-stat & $\begin{array}{c}\text { Estimation } 2 \\
\text { Logit }\end{array}$ & Estimation 2 z-stat \\
\hline C & -2.41 & $2.74^{\star \star}$ & -1.74 & 1.91 \\
\hline D CADP & 0.25 & 1.37 & -0.58 & 1.12 \\
\hline D African & & & -0.87 & $4.73^{\star *}$ \\
\hline D African ${ }^{*}$ C CADP & & & 1.27 & $2.38^{*}$ \\
\hline D Indian & & & -0.92 & $5.72^{* *}$ \\
\hline D Indian*D CADP & & & 0.50 & 0.66 \\
\hline D Coloured & & & -0.80 & $5.86^{* *}$ \\
\hline D COHR & 0.13 & 0.88 & 0.25 & 1.50 \\
\hline$D$ COHR*D CADP & & & -0.17 & 0.32 \\
\hline D DET & 0.10 & 0.46 & -0.03 & 0.11 \\
\hline D DET*D CADP & & & -0.04 & 0.10 \\
\hline Adjmatpt & 0.16 & $11.1^{* *}$ & 0.16 & $11.05^{\star \star}$ \\
\hline D Eng FL HG & 0.27 & 1.33 & 0.30 & 1.49 \\
\hline D Math HG & 0.43 & $3.79^{* \star}$ & 0.45 & $3.93^{* *}$ \\
\hline D PSHG & 0.52 & $5.10^{* *}$ & 0.52 & $5.00^{\star \star}$ \\
\hline Age & -0.09 & $-2.37^{*}$ & -0.09 & $2.19^{*}$ \\
\hline D English home & 0.09 & 0.70 & 0.15 & 0.84 \\
\hline D Male & 0.02 & 0.19 & 0.02 & 0.23 \\
\hline D White & 0.89 & $8.12^{*}$ & & \\
\hline D Year 2000 & -0.27 & $2.19^{*}$ & -0.25 & $2.04^{*}$ \\
\hline D Year 2001 & -0.77 & $6.31^{* *}$ & -0.76 & $6.28^{* \star}$ \\
\hline D Year 2002 & -0.22 & 1.77 & -0.22 & 1.73 \\
\hline McFadden R2 & 0.140 & & 0.143 & \\
\hline Observations & 3655 & 3655 & 3655 & 3655 \\
\hline
\end{tabular}

Notes: ** and * represent statistical significance at $1 \%$ and $5 \%$ levels, respectively. The QML (Huber/White) standards errors and covariance used for the estimations.

For estimation 1 the coefficient of the CADP dummy is positive but statistically insignificant. This result contrasts with that achieved using the propensity score matching technique and suggests that the graduation rate for students on the CADP is similar to mainstream students conditional on the independent variables. The variables, adjusted matriculation points score (Adjmatpt), mathematics (HG) (D Math $H G$ ), physical science (HG) (D PSHG), age and whether the student was previously classified as 'white', are statistically significant at least at the 5 per cent level in explaining whether the students graduated or not. With the exception of age the coefficients have a positive sign and are consistent with the priors. This suggests that academic ability, as measured by the students' adjusted 
matriculation points score and whether they took mathematics (HG) and physical science (HG), plays an important role in determining whether students graduate or not. In addition, students previously classified as 'white' are also more likely to graduate conditional on the other explanatory variables. The finding that older students are less likely to graduate, conditional on the other variables, may warrant further investigation. It is noted that the coefficients for the DET and COHR dummies are statistically insignificant. This suggests that students from these schools had graduation rates on a par with students from other types of schools conditional on the other independent variables. The coefficients for each of the years 2000 and 2001 are negative and statistically significant at least at the 5 per cent level. The students in each of these two cohorts have lower graduation rates than the students of the 1999 cohort. Finally, it is noted that the McFadden $\mathrm{R}^{2}$ is 0.14 ; the independent variables only account for 14 per cent of the variation in the graduation rate. This implies that there are several omitted variables that may help to explain the variation in the graduation rate.

Turning to estimation 2, African (D African), 'coloured' (D Coloured) and Indian (D Indian) students all exhibit lower graduation rates than white students, and the difference is statistically significant at the 1 per cent level. However, the interaction term, African* DCADP is positive and statistically significant at the 5 per cent level. The graduation rate for African students on the CADP is greater than for their peers on the mainstream conditional on the independent variables. This suggests that the CADP adds value for African students, but not for Indian students or those previously classified as 'coloured'. This result warrants further investigation especially as 168 of the 227 CADP students (74\%) are African. It is also noted that the coefficients for interaction terms, $D D E T * D C A D P$ and $D$ $C O H{ }^{*} D C A D P$, are statistically insignificant. This implies that students from former DET or COHR schools, who are part of the CADP cohort, attain similar graduation rates to mainstream students conditional on the other independent variables.

It should also be borne in mind that members of the CADP cohort are subject to a number of educational and socioeconomic disadvantages that are generally not experienced by mainstream students and which are not captured by the independent variables. For example, area of residence, home environment, financial constraints and a general low level of academic preparedness necessary to make a success of academic study at the tertiary level, which may not be measured by matriculation results, school attended or specific subject characteristics. Therefore, these findings lend support to the view that the CADP has been successful in enabling students to overcome some of their educational and socioeconomic disadvantages relative to mainstream students.

It should also be noted that the CADP gave 227 students the opportunity of attempting a degree programme of whom 100 graduated. Without the CADP these 100 students would not have been admitted to the university and they would not have graduated. 


\section{IMPLICATIONS FOR HIGHER EDUCATION POLICY IN SOUTH AFRICA}

As noted in the introduction, a variety of academic support initiatives are offered to students from academically disadvantaged backgrounds at tertiary institutions in South Africa. The findings of this study suggest that appropriate educational interventions in the student's first year at a tertiary institution may impact positively on their academic performance through to graduation. In particular the type of educational interventions implemented in the accounting, economics, statistics and information systems courses may have enabled students to profit, not only in these courses, but in further courses in these and other subjects.

The chief emphasis of the educational interventions was to improve students' writing, quantitative, learning and study skills; these are skills that may enable students to achieve greater success in subsequent higher-level courses (Smith 2004; Smith 2007). That said this study does not clarify the importance of each of the interventions in improving student performance. It only suggests that the interventions, in some combination, had the effect of improving students' graduation rates, relative to mainstream students. Further investigations are required to tease out the effects of the various interventions on students' academic performance through to graduation.

These findings also have implications for higher education policy in general in South Africa. Graduation rates across the tertiary sector are a grave cause for concern (Scott et al. 2007). It is not unreasonable to assume that many students on mainstream courses and programmes would benefit from a similar array of educational interventions, given that many of them have barely qualified for mainstream courses (Smith 2004).

The investigation of the effects of increasing the nature and number of interventions under the umbrella of the CADP, referred to above, may throw more light on whether such an investment in academically disadvantaged students is justified in terms of their improved performance through to graduation. It may also provide additional evidence of the types of interventions that may prove useful in improving the performance of mainstream students.

\section{CONCLUSION}

This article investigates the effectiveness of the first-year academic development courses in economics, statistics, information systems and accounting, offered by the CADP, in improving the graduation rates of students from educationally and socio-economically disadvantaged backgrounds. The article adds to the literature on the subject in three ways. Firstly, studies focusing on the effectiveness of academic development programmes in improving students' graduation rates are rarely reported in the South African or international literature. Secondly, the sample-selection problem is acknowledged and the propensity score matching technique is used explicitly to deal with this issue. Thirdly, a number of independent variables are identified, which help to explain whether a student graduates or not. 
The results suggest that the first-year academic development courses have a positive effect on students' graduation rates relative to a control group drawn from the mainstream. The results also suggest that the impact of the CADP is most pronounced for African students. This latter finding warrants further investigation especially as these students make up 74 per cent of the CADP cohort. Further, students' academic ability, as measured by their matriculation examination performance, is an important determinant of graduation success.

Other important determinants are whether the student was previously classified as white' and their age on first entry into the university. Finally, these findings suggest that academic development programmes may have a positive role to play in improving graduation rates of previously disadvantaged students. Tertiary institutions in South Africa may be able to improve the graduation rates of disadvantaged students by introducing first-year courses, that give students the opportunity to acquire writing, language, quantitative, learning and study skills, under the umbrella of an academic development programme.

\section{NOTES}

1 'Mainstream' refers to those courses that make-up the standard three-and four-year degree programmes in the commerce faculty.

2 At the University of Lesotho first-year courses are transitional courses which do not count towards the final degree. However, these marks determine whether the student is accepted onto the degree programme or not.

3 The Department of Education and Training, formerly known as the Department of Bantu Education, had responsibility for the education of African children from 1954 to 1994.

4 The admission rating was calculated on the basis of points awarded for each grade achieved in the matriculation examination on either higher or standard grade for each subject.

5 The University of Cape Town allocates points to matriculation subjects as follows:

Higher Grade (HG): A=8, B=7, C=6, D=5, E=4, F=3. Standard Grade (SG): Two points less for each grade.

6 There is an extensive literature on sample-selection problems - this literature includes Park

and Kerr (1990) and Raimondo, Esposito and Gershenberg (1990).

7 At least 95 per cent of the CADP cohort are South African citizens who wrote the matriculation examination set by one of the nine provinces.

8 psmatch2 CADP Matpt Age COHR DET Enghome Male Year 2000 Year2001 Year 2002, kernel outcome (Graduated) 


\section{REFERENCES}

Adelman, C. 1999. Answers in the toolbox: Academic intensity, attendance patterns, and bachelor's degree attainment. Education Publications Centre, U.S. Department of Education.

Ayaya, O. O. 1996. The prediction of academic performance in the first-year: a case study at the National University of Lesotho. South African Journal of Higher Education 10 (2): 101-113.

Banach, J., L. Fuzile and W. Rampedi. 1992. Some pointers to causes of failure by African students in economics. SAAAD 92: Proceedings of the $7^{\text {th }}$ conference of the South African Association for Academic Development, Port Elizabeth Technikon, 3-5 December 1992.

Bettinger, E. P. and T. L. Long. 2005. Addressing the needs of under-prepared students in higher education: Does college remediation work? National Bureau of Economic Research, Working Paper 11325. . 2006.

Institutional responses to reduce inequalities in college outcomes: Remedial and developmental courses in higher education. Economic Inequality in Higher Education: Access, Persistence and Success. Russell Sage Foundation Press, New York.

Boylan, H. R. and D. P. Saxon. 1999. Outcomes of remediation. Available at: http:/www. ncde.appstate.edu/reserve_reading/Outcome_of_Remediation.htm. Accessed on 25 May, 2008.

Brothen, T. and C. A. Wambach. 2004. Refocusing developmental education. Journal of Developmental Education 28 (2): 18-33.

Curtis, P. J. D. and J. de Villiers.1992. The academic effectiveness of a bridging year for commerce undergraduates. Development Southern Africa 9 (November): 457-470.

De Villiers, J. and H. Rwigema. 1998. The effect of a bridging year on the graduation success of educationally disadvantaged commerce students. South African Journal of Higher Education 12 (1): 103-108.

Edwards, L. 2000. An econometric evaluation of academic development programmes in economics. South African Journal of Economics 68 (3): 455-483.

Hay, H. R. and F. Marais. 2004. Bridging programmes: Gain, pain or all in vain. South African Journal of Higher Education 18 (2): 34-58.

Hesketh, J., C. Mbali, and N. Mkhize. 1994. What makes them fail? An investigation into Economics 1A. Proceedings of the $9^{\text {th }}$ conference of the South African Association for Academic Development, University of Natal, Durban.

Levin, H. M. and J. C. Calcagno. 2008. Remediation in the community college: An evaluator's perspective. Community College Review 35:181-207.

MacDonald, R. B. and M. F. O'Hear. 1996. A critical review of research in developmental education: Part 2. Journal of Developmental Education 19 (3): 8-14.

McConnell, C. 1980. Economics 101: Where do we stand? Journal of Economic Education 12 (1): 15-22.

O'Hear, M. F. and R. B. MacDonald. 1995. A critical review of research in developmental education: Part 1. Journal of Developmental Education 19 (2): 2-6.

Park, K. H. and P. Kerr. 1990. Determinants of academic performance: A multinomial approach. Journal of Economic Education 21 (2): 101-111.

Parker, K. 2006. The effect of student characteristics on achievement in introductory microeconomics in South Africa. South African Journal of Economics 74 (1): 137-149. Tay, 
Pym, J. 2007. Understanding and responding to specific learning styles, needs and contexts: What makes a difference? The International Journal of Learning 14(8).

Raimondo, H. J., L. Espito and I. Gershenberg. 1990. Introductory class size and student performance in intermediate theory courses. Journal of Economic Education 21 (4): 369-381.

Ramirez, G. M. 1997. Supplemental instruction: The longterm impact. Journal of Developmental Education 21 (1): 2-9.

Saxon, D. P. and H. R. Boylan. 2001. Cost of remedial education in higher education. Journal of Developmental Education 25 (2): 2-8.

Scott, I., N. Yeld and J. Hendry. 2007. A case for improving teaching and learning in South African higher education. HE Monitor 6 (October).

Smith, L. C. 2004. A multivariate evaluation of mainstream and academic development courses in first-year microeconomics at the University of Cape Town: A comparative study. Masters dissertation, University of Cape Town. . 2009. An analysis of the impact of pedagogic interventions in first-year academic development and mainstream courses in microeconomics. South African Journal of Economics 77 (1): 162178.

Smith L. C. and L. Edwards. 2007. A multivariate evaluation of mainstream and academic

development courses in first-year microeconomics. South African Journal of Economics 75 (1): 99-117.

R. 1994. Students' performance in economics: Does the norm hold across cultural and institutional settings? Journal of Economic Education 25 (4): 291-301.

Terreblanche, S. 2002. A history of inequality in South Africa 1652-2002. University of Natal Press, Scottsville and KMM Review Publishing, Sandton.

Van Walbeek, C. 2004. Does lecture attendance matter? Some observations from a first-year economics course at the University of Cape Town. South African Journal of Economics 72 (3): 11-32.

Visser, A. J. and M. Hanslo. 2005. Approaches to predictive studies: Possibilities and challenges. South African Journal of Higher Education 19 (6): 1160-1176.

Volbrecht, T. 1999. Mainstreaming academic development at the University of the Western Cape: A case of 'Mission Impossible' or just 'Messiness Inevitable'? Academic Development 3(1).

Walker, M. and N. Badsha. 1993. Academic development and the challenge of curriculum change at the University of the Western Cape: An overview. AD Dialogues 1:1-14.

Weismann, J., C. Bulakowski and M. K. Jumisko. 1997. Using research to evaluate developmental education programs and policies. New Directions for Community Colleges 100:73-80. 